\title{
Exploring Principal's Leadership Competencies in Academic and Administrative Areas at Govt. Secondary Schools in the Province Khyber Pakhtunkhwa
}

\author{
* Gauhar Zaman, PhD Scholar (Corresponding Author) \\ ** Dr. Saqib Shehzad, Associate Professor \\ *** Dr. Hafiz M. Irshadullah, Assistant Professor
}

\begin{abstract}
The present study has been conducted for the identification of Principals leadership's competencies in academic and administrative areas at the secondary school level of education in Khyber Pakhtunkhwa. The population of this research study encompasses all 1422 Secondary School Principals. Random sampling technique was applied to select 377 school heads as respondents. To conduct the research study, data was collected through questionnaires, which were further tabulated for analysis through Statistical Package for Social Sciences (SPSS), and analytical tools of mean, standard deviation, and correlation were used. It is found that the majority of the respondents responded that they had properly managed human resources, and performed academic and administrative activities for the promotion of education in the institutions. It is recommended that the level of leadership in administrative and academic areas be improved with modern approaches.
\end{abstract}

Keywords: Principal's leadership, Competencies, Secondary level.

\section{Introduction}

The significance of an effective and proficient school principal is accepted globally. Indeed, the school principal is always a senior-most person, administrator, and school manager providing guidance to staff of the school and also running routine affairs of the school. The administration is a branch of the employees of the school or university responsible for the maintenance and supervision of the institution and separated from the teaching staff or academics. Sometimes several staff members may have both administrative and academic tasks. The educational environment of a school is a practice while its educational achievement is regarded as a result of this environment. A lot of academics have worked on exploring the connection between leadership competencies of school heads and their educational achievements. This paper explores how an ideal or perfect school principal maybe.

Leadership is a multifaceted job that demands many qualities from in an individual; knowledgeable, experienced, analytical mind, and decision power. In literature, there is no such standard definition for a school principal but its main concern is operational and managerial. Academic organizations need the administration to arrange, plan, guide, and appraise daily tasks to attain the educational objectives utilizing coordinating personnel and allotted budgets.

It is noted that all principals possess all or few leadership competencies. Such competencies affect the overall school environment including academic activities and administration. There is a dire need to explore those competencies which are related to the administration and academic spectrum that exists in our school's leadership. Therefore, the study exploring principal's leadership competencies in academic and administrative areas at the secondary level of education in Khyber Pakhtunkhwa province is undertaken which is of paramount importance.

Identification of Principals leadership's competencies in academic and administrative areas at the secondary level of education in Khyber Pakhtunkhwa province of Pakistan is the main objective of the study

The current research study might be noteworthy as the scholar explored an innovative viewpoint about the Principals' leadership competencies. It would also be noteworthy for other

\footnotetext{
* Department of Education, Abdul Wali Khan University Mardan Email: pfgphsrsc@yahoo.com

** Department of Education, Abdul Wali Khan University Mardan

*** Department of Education, Abdul Wali Khan University Mardan
} 
researchers to find out more new facts related to this area for the provision of guidance and support to policymakers in the field of education.

This Research Study was delimited to Govt. Boys Secondary Schools in Khyber Pakhtunkhwa due to time and financial constraints. Convenient sampling techniques were considered best for selecting a sample for the study. $25 \%$ of the total districts were taken as samples, which allowed us to select five out of 25 districts for the study. Hence, schools of five districts Karak, Mansehra, Mardan, Nowshera, and Swabi were chosen for collecting data as a sample of the study.

\section{Literature Review}

Generally, Leadership may be defined as a practice by which an individual puts an impression on other persons or assemblages of persons for the attainment of a collective goal (Peter, 2007; Gary, 2008). Gary describes numerous features of leadership phenomenon. Some of these features include: (a) it is considered a continuous process, (b) this phenomenon impacts other people, (c) leadership is associated to collective behavior, (d) it is associated with the achievement of certain goals, and (e) attainment of objectives, as a result, leadership are common for the group leader and its participants. Being a process, leadership is not such a feature or trait, transmitted by inheritance. As a practice, leadership is a transferable process between the group leader and the subordinate group members.

Leadership is also regarded as an influential phenomenon, which influences group members, peers and leader itself in a directorial environment. Indeed, influencing and leadership are mutually associated. Leadership functions in an assemblage of people having common goals and objectives. Achievement of certain goals is the outcome of leadership. Leadership gives a direction to people towards the completion of admission. It provides a strategy for reaching a goal through a fair approach. Leadership involves a mutual interactive procedure, so leaders not only direct their potentials for the accomplishment of a certain task, as well as strengthens their team members.

Mulford (2007) describes that the present age is a golden period in terms of school leadership. Keeping in view the significance of leadership, many governments in the world are investing funds and resources for researching this field. Workshops and training agendas are arranged on this theme for school organizers. For example, England is very seriously working on this. They have established a reputable institution for effective training of educational leadership, namely, NCSL (National College for School Leadership). These institutions are running different programs for the proper training of organizers and leaders. They are also working on the modernization of their existing methods in this context. (Day\&Leithwood, 2007).

Leadwood, Day, Sammons, Harris \& Hopkins (2006) think that school leadership plays an effective role in schools. Education and classroom instruction has a primary position in schools, while educational leadership is vital for the healthier achievement of these goals. Research conducted in the United Kingdom (Whelan, 2009) describes that out of every one hundred (100) healthy managed educational institutions, 93 educational institutions have first-class achievements. In the same way, out of every 100 schools that are not supervised well, only one has a good level of student achievement. Based on the research work of Pierson (2014), it is outlined that students' outcomes can be affected by school principal which is indirectly affecting other school staff including teachers, school and classroom environments, and outreach to families and communities.

Bennis (1987) cited Thach et al., (2007) describe that some of the leadership traits are extremely necessary for each leader. Some of these competencies contain the capability of societal abilities and a powerful strength for the attainment of objectives. Systematic skills and self-awareness related to the profession are also a portion of the leadership proficiencies. Moreover, often cited capabilities include: consistency, scientific proficiency, communication, diversity mindfulness, change management, developing others, emphasize goals, problem-solving abilities, strong decisive power, administrative sharpness, calculated intellectual, customer attention, proficient skills, group governance, influential abilities, resolving differences in a harmonious manner, responsive intellect, communal and environmentally responsible, dependency on the principles of the educational institutions even humor and novelty. Trinka (2004), Thach et al., (2007), Spencer \& Spencer (1993). Some minor modifications are also occurring in public (not for profit) and profit leadership competencies models. Public leadership competencies emphasize upon managerial potentials, for example, boardroom involvement, power efficacy and serving society etc (Chait, Ryan and Taylor (2004) cited in Thach et al., (2007)). While profitable organizations emphases on managerial capabilities such as monetary accountability and concern as associated with a public organization. 
Public managed administrations emphasis on physical well-being, durability, as well as administrative sharpness etc more comparing to profitable organization. (Horey\&Fallesen, 2003, cited in Thach et al., 2007; OPM, 1992).

Cognitive competencies arise due to Systematic Knowledge, comprising the notions of impulsive occurrences at the imbedded level of knowledge. Medves (2006) explained that the training of cognitive competency is mainly influenced by the educational environment. Cognitive competencies include the management of universal values, concepts, philosophies, and laws. Predominantly noteworthy cognitive competencies are:

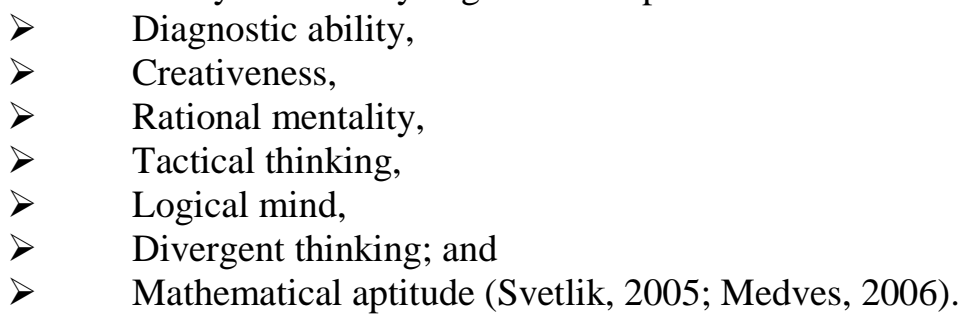

Functional competencies are caused due to procedural understanding (Medveš, 2006). Such competencies are comprised to perform a concrete activity, experiences, and skills that are required for an individual to day-to-day problem-solving process. Most significant functional competencies are listed below:

$>$ Communication aptitude,

$>\quad$ Technical ability (IT, media, etc.),

$>\quad$ Language skills

$>\quad$ Global competencies

$>\quad$ Learning skills and individual growth,

$>\quad$ Professional forecasting skill,

$>\quad$ Administrative abilities, and

$>\quad$ Judgmental ability (Svetlik, 2005; Medves, 2006).

$>\quad$ International environment abilities, and

D Globalization awareness (Harris, 2001; Manning, 2003; Jokinen, 2005; Suutari, 2002; May, 1997).

Individual and Social qualities are those traits that allow a person to create and preserve the relationship with other individuals. Particularly, significant personal and social competencies are:

$>\quad$ Self-determination,

$>\quad$ Social skills,

$>\quad$ Collaborative proficiency,

$>$ Consideration,

$>\quad$ Integrity / Honesty,

$>\quad$ Organizational skills,

$>\quad$ Individual and communal standards, and

$>\quad$ Moral magnitude (Svetlik, 2005; Medves, 2006).

$>\quad$ Character, originality, and empathy (Allio, 2005).

School Leadership is carried out by school principals. The range of role of the principal is from the management of the school business to community-school relations. The prime role of the principal is not only the curriculum supervision but also the management of material resources. A great controversy exists regarding the role of the principal among different scholars. Some scholars consider him as an administrator, while others declare him as a leader.

The leadership role is crucial in the school academic environment (Lashway, 2003). Development and nourishment of the vision, encouraging a safe and well-managed school, sustaining consistency expansion, utilizing a data-driven plan for enhancement of students' performance, using quality assessments techniques, monitoring plan, handling school resources, and productive communication with other stakeholders are the signs of the strong school leadership. Lashway (2003) supports the assistance of upper level in favor of school leadership and facilitate them to framework a policy, preparing the plan, and proper resource. The leadership of low academic achieving school needs to work in partnership with teachers to progress educational attainment and stimulate the ethos of engaging teachers in decision- making process to shape a novel role. Based on his research, 
Lashway (2003) found that students improved the performance in schools when certain practices were implemented. One of these practices was transforming schools through active engagement and principal leadership.

The researcher of this study realized that the schools' leaders of Khyber Pakhtunkhwa face challenges in improving school performance, as demanded by the provincial educational ministry, within the implemented accountability system (Elmore, 2000; Elmore \& Fuhrman, 2001). Lashway (2003) mentioned that achieving this standard, although frustrating, itself can be helpful to guide the school leadership practices. Based on another research study of Lashway (2003), effective school leadership leads the transformation of schools with a positive climate, effectual instruction, increases the involvement of parents, and increases the achievements of students. Previous research reveals that the demand of improving school academic achievements, which is placed upon school leaders, cannot be overcome without the support of teamwork as noted by Reeves (2006) during his research studies that attaining perfection is not only an essential challenge of the school leader but also the acknowledgment of imperfection and gaining complementariness is the challenge. Elmore (2000) noticed that great principals simultaneously develop teams that never imitate the principal. In this way, school leadership develops into "distributive" in nature.

As an effective leader, the school principal put the school in the right direction, and allows the distributive nature learning community for improvement of a "common culture of expectations." In consequence, the principal school leader can tie together the "power of collective intelligence" (DuFour et al., 2004); to reinforce the proficient learning community in its sagacity of purpose and mission to assemble the teachers' needs of learning and as well as of students.

It is worthy to mention that the school principals, whether administrators or leaders, are the motivating strength behind effective schools. Learning Teaching process is carried out with different methods of ineffective schools (Hopkins, Ainscow and West, 1994). School principal supervises the overall school programs and responsible for the whole school performance, expertise, and efficiency (Wango, 2006). Being head of the school and an administrator, the principal must be an effective and responsible person. He is accountable for encouraging effective teaching in the school as a leader of the teaching faculty (Okumbe, 1998). All these are done by him by appointing qualified employees and competent teaching staff in the school. Besides these responsibilities, the head of the school should also be an extremely proficient and skillful person in contemporary approaches of classroom management, classroom teaching, and allocation of duties, human resource management, and communication (Mbiti, 1974).

The school principal has an important position in influencing the human aspects of morale in maintaining human relations with the community. For getting support for the school programs, he must keep in mind the community and social settings such as power structure and pressure groups. The head of the school must be answerable to the community. He will be aware of the procedure and tactics of making them interested in what their offspring are doing in the school environment (Mbiti, 1974).

\section{Method}

According to the Educational Management Information System, EMIS (2016), there are 1422 Secondary school principals in Khyber Pakhtunkhwa which make the population for this research. A sample of three hundred and seventy-seven (377) school heads were selected randomly from five districts; Mardan, Swabi, Nowshera, Karak, and Mansehra. A Likert scale questionnaire was developed for principals for data collection. The study was discovering leadership competencies of principals in school administrative and academic areas of secondary schools. Information was collected and tabulated for analysis through the Statistical Package for Social Sciences (SPSS) program. Mean and standard deviation were calculated after the tabulation of the data.

\section{Results}

The goals and objectives of the research study were evaluated by the following table, showing the analysis and interpretation of the statements replied by school heads.

Table: Leadership Competencies of School Principals in Administrative and Academic Areas

\begin{tabular}{clccc}
\hline S.No. & \multicolumn{1}{c}{ Statements } & N & Mean & Std. Deviation \\
\hline $\mathbf{1}$ & $\begin{array}{l}\text { "Staff autonomy is supported for benefitting the school } \\
\text { educational environment." }\end{array}$ & 95 & 3.62 & .980 \\
$\mathbf{2}$ & "Human resources are properly managed to enhance the school & 95 & 3.86 & 1.199
\end{tabular}




\begin{tabular}{|c|c|c|c|c|}
\hline & academic environment." & & & \\
\hline 3 & "Teachers are internally motivated to be regular and diligent." & 95 & 3.96 & 1.228 \\
\hline 4 & $\begin{array}{l}\text { "School staff members are always consulted for seeking better } \\
\text { advice, guidance, and feedback to innovate the school academic } \\
\text { process." }\end{array}$ & 95 & 3.14 & 1.117 \\
\hline 5 & $\begin{array}{l}\text { "Staff is appreciated for better coherence and collaboration to } \\
\text { achieve the goals of the school." }\end{array}$ & 95 & 3.76 & 1.302 \\
\hline 6 & $\begin{array}{l}\text { "Teachers' performance, teaching according to the yearly class- } \\
\text { wise syllabus, is assessed every month." }\end{array}$ & 95 & 3.65 & 1.335 \\
\hline 7 & $\begin{array}{l}\text { "Students who perform well academically, are appreciated to } \\
\text { enhance the school academic environment." }\end{array}$ & 95 & 3.91 & 1.459 \\
\hline 8 & $\begin{array}{l}\text { "Annual school audit (internally) is carried out to prevent any } \\
\text { kind of irregularities in the school budget." }\end{array}$ & 95 & 3.76 & 1.319 \\
\hline 9 & $\begin{array}{l}\text { "There is a well-managed procedure to run the school income } \\
\text { and expenditures matters." }\end{array}$ & 92 & 3.55 & 1.270 \\
\hline 10 & $\begin{array}{l}\text { "The issues that are raised, individually or in a group are } \\
\text { resolved to enhance the efficiency of the school." }\end{array}$ & 95 & 3.61 & 1.323 \\
\hline 11 & $\begin{array}{l}\text { "Good balance is maintained between externally assigned } \\
\text { official duties and school duties to run the educational process } \\
\text { smoothly." }\end{array}$ & 95 & 4.17 & .953 \\
\hline 12 & "School duties are preferred over individual activities." & 95 & 4.00 & 1.072 \\
\hline 13 & $\begin{array}{l}\text { "The setting, management plan, and assigning responsibilities } \\
\text { are reshuffled every year to keep the academic environment } \\
\text { smooth and progressive." }\end{array}$ & 95 & 3.85 & .978 \\
\hline 14 & $\begin{array}{l}\text { "The selection of right men, for the right job, on the right time is } \\
\text { done to run the school affairs and activities smoothly." }\end{array}$ & 95 & 3.74 & 1.446 \\
\hline \multirow[t]{2}{*}{15} & $\begin{array}{l}\text { "Formative and summative evaluation techniques are supervised } \\
\text { for impressive results of the school's educational output." }\end{array}$ & 95 & 3.83 & 1.310 \\
\hline & Average of Means & & 3.76 & \\
\hline
\end{tabular}

For the accurate and precise interpretation of data, the Average of means were calculated. The following data analysis and interpretation procedures were drawn from the above table:

If the mean of the statement is equivalent to the value of average mean "3.76", then leadership competency is practicable. The mean of any statement in ranging between 3.5-3.75 shows that a significant integer of schools' principals retains that specific leadership competency. The mean of the statements in between the range 3.77-4.40 indicates the agreement of respondents with the statement which exposes that particular leadership competency is practicable by the majority of the school heads. The mean of the statements in between 4.50 to 5.00 range concludes that the respondents are robustly agreed, exposing that particular leadership competency is possessing by all school heads. Mean of the statements in the range 2.50-3.40 shows the uncertainty of respondents about that leadership competency. Whereas, specific leadership competency is not possessed by the school principals, if the mean of the statement lies in the range of 1.00-2.40.

Keeping in view the above-mentioned considerations, table concludes that leadership competencies of "appreciation for better coherence and collaboration to achieve the goals of the school", and "carrying out annual internal audit of school to prevent any kind of irregularities in the school budget" are possessed up to somehow by the school principals with consecutive mean 3.76 having Std. Deviation 1.302, and mean 3.76 having Std. Deviation 1.319= average mean 3.76.

Other leadership competencies like "Supporting staff autonomy for the benefit of the school educational environment." with mean 3.62 having Std. Deviation .980, "assessing teachers' performance monthly who teach according to school's yearly class-wise syllabus" with mean 3.65 having Std. Deviation 1.335, "establishing a well-managed system to run the school income and expenditure matters" with mean 3.55 having Std. Deviation 1.270, "resolving issues of the staff to enhance their efficiency" with mean 3.61 having Std. Deviation 1.323, and "selection of right men for the right job at the right time." with mean 3.74 having Std. Deviation 1.446 lies in 3.50-3.75 range which exposes that a substantial amount of respondents approved that particular competencies are practicable by the school principals.

Some findings and conclusions of table disclose that the majority of the school heads are agreed with leadership competencies, "human resources are properly managed to enhance the school 
academic environment" showing mean 3.86 with S.D 1.199, "good balance is maintained between externally assigned official duties and school duties to run the educational process smoothly" with 4.17 mean and 4.17 S.D, " school duties are preferred over individual activities" showing 4.00 mean, having an S.D of 1.072, and " the setting, management plan and assigning responsibilities are reshuffled every year to keep the academic environment smooth and progressive" mean value of 3.85 having .978 S.D value lying in the range of 3.77 to 4.50 .

Interpretation of collected data also reveals that uncertainty exists among the maximum number of respondents on the competency, "school staff members are always consulted for seeking better advice, guidance, and feedback to innovate the school academic process". Here, the mean of the statement lies in between the range of 2.50 to 3.40. It shows that a lot number of school principals have no awareness of whether this particular leadership competency is practiced by them or not.

\section{Discussion}

The study examined the Leadership Competencies of secondary school principals in educational and managerial activities. This study also revealed that the school principal's leadership is very crucial and supported the idea that the competency of supporting staff autonomy is almost there in every school head. It is found that the competency of appreciating academic and supporting staff for better management and forming an effective chain to maximize the results is majorly there in school principals. School heads possess the quality of conducting annual interior audits of the school so to check any kind of abnormalities in the monetary matters. It is maintained vehemently by almost all heads that they prefer official duty over their engagements. Human resources management competency is held there for the proper management to progress the school academic environment. Teachers are internally encouraged to be consistent and attentive. The analysis showed that the school principal's leadership competencies in academic areas are also evident. Performance of teachers, education based on yearly planner are evaluated regularly. Students shown excellent performance in academics are valued, which further improves the school educational environment. The study exposed that the proper management of human resources competency is found which ensures an efficient instructional environment. It is found that the school heads are quite proficient in possessing the ability to manage the school settings, managing academic plans and assigning responsibilities. They are also efficient in reshuffling these settings every year to keep the educational environment charming and enlightened.

The study also publicized that the majority of the respondents are uncertain on the leadership competencies that staff members of the school (academic and administrative) are always referred for seeking healthier opinion, supervision, and feedback to progress school academic practice.

\section{Conclusions}

Tabulation, evaluation, and interpretation based on the collected data related to the study leads to the following conclusions:

The majority of the secondary school principals in the province of Khyber Pakhtunkhwa use leadership competencies in administrative and academic areas of their concerned institutions. Research study reveals that good quality connection between the school's principal and staff leads to constructive schools' educational performance.

Most of the principals responded that facilitating students to learn as well as teachers to teach progresses academic atmosphere. The majority of the respondents suggested that the matters raising individually or collectively are fixed to improve the efficacy of the institution.

The majority of the principals suggested that there exists a well-administered process to route the school earnings and expenses matters. It is evident that most of the school heads were uncertain on the leadership competencies that school staffs are constantly consulted for seeking healthier assistance, direction, and opinion to progress the running process of the school.

\section{Recommendations}

The current study shows that school principals of secondary schools in Khyber Pakhtunkhwa use leadership competencies in academic and administrative areas. It is found that school heads do not possess the competency of being democratic in decision making in schools. Therefore, it is recommended that such qualities may be polished and enhanced through regular trainings and workshops to cope with issues that arise from the difference of opinion about a certain issue in the school setting. The current study was conducted in Khyber Pakhtunkhwa at secondary school level of education; it is suggested that it may be conducted in other provinces and at various levels i.e. at 
college and university level. For further studies on the subject, data collection tools other than questionnaires may be used. The same study may also be carried out in girls' schools of Khyber Pakhtunkhwa.

\section{References}

Ainsa, P. (2011). "Critical pedagogy towards a socio moral classroom”. Journal of Instructional Psychology, 38(2), 84-92.

Attle, S. (2007)."Cooperative Learning in a Competitive Environment: "International Journal of Teaching and Learning in Higher Education, Number 1, 77-83.

Baldi, S., Skidmore, D., Greenberg, E., \& Hahn C. (2001). What democracy means to ninth graders: US results from the international IEA civic education study. Washington, DC: National Center for Education Statistics. Available at: http://nces.ed.gov/surveys/cived.

Basu, S. J., \& Barton, A. C. (2010).A researcher-student-teacher model for democratic science pedagogy: Connections to community, shared authority, and critical science agency. Equity \& Excellence in Education, 43(1), 72-87.

Bronfenbrenner, U. (1977). Toward an experimental ecology of human development. American Psychologist. July 1977, 513-531.

Dewey, J. (1961). Democracy and Education: an introduction to the philosophy of education. Macmillan Paper books Edition, the Macmillan Company, New York, p.p 81-99.

EMIS, (2013). Government of KPK, Elementary \& Secondary Education Department, retrieved on $25^{\text {th }}$ August 2012, http://www.kpese.gov.pk/home/view.cfm?MenuID1.

Glasser, W. (1990).The quality school: Managing students without coercion. New York: Harper \& Row.

Golash, D. (2010). Freedom of expression in a diverse world. Dordrecht: Springer.

Hahn, C. (2001). Student views of democracy: The good and bad news. Social Education, 65 (7), 456459.

Lippitt, R. \& Gold, M. (1959).Classroom Social Structure as a Mental Health Problem. Journal of Social Issues, Vol, (15),40-58.

Miller, A \& Cunningham, K (2011).Classroom Environment. Retrieved on $29^{\text {th }}$ August, 2013 from http://www.education.com/reference/article/classroom-environment.

Muntner, M. (2008).Teacher-Student Interactions: The Key To Quality Classrooms. The University of Virginia Center for Advanced Study of Teaching and Learning (CASTL).

Patrick, H., Ryan, A., \& Kaplan, A. (2007).Early adolescents' perceptions of the classroom social environment, motivational beliefs, and engagement. Journal of Educational Psychology, 99, 83-98.

Slavin, R. E. (2008).Cooperative learning, success for all, and evidence-based reform in education. In Education etdidactique, vol 2/2008, 149-157.

States News Service, (2010).Scholastic and Bill and Melinda Gates Foundation, USA, Washington. 